\title{
Importance of correcting for individual differences in the clinical diagnosis of gait disorders
}

Citation for published version (APA):

Senden, R., Meijer, K., Heyligers, I. C., Savelberg, H. H., \& Grimm, B. (2012). Importance of correcting for individual differences in the clinical diagnosis of gait disorders. Physiotherapy, 98(4), 325-329. https://doi.org/10.1016/j.physio.2011.06.002

Document status and date:

Published: 01/12/2012

DOI:

10.1016/j.physio.2011.06.002

Document Version:

Publisher's PDF, also known as Version of record

Document license:

Taverne

Please check the document version of this publication:

- A submitted manuscript is the version of the article upon submission and before peer-review. There can be important differences between the submitted version and the official published version of record.

People interested in the research are advised to contact the author for the final version of the publication, or visit the DOI to the publisher's website.

- The final author version and the galley proof are versions of the publication after peer review.

- The final published version features the final layout of the paper including the volume, issue and page numbers.

Link to publication

\footnotetext{
General rights rights.

- You may freely distribute the URL identifying the publication in the public portal. please follow below link for the End User Agreement:

www.umlib.nl/taverne-license

Take down policy

If you believe that this document breaches copyright please contact us at:

repository@maastrichtuniversity.nl

providing details and we will investigate your claim.
}

Copyright and moral rights for the publications made accessible in the public portal are retained by the authors and/or other copyright owners and it is a condition of accessing publications that users recognise and abide by the legal requirements associated with these

- Users may download and print one copy of any publication from the public portal for the purpose of private study or research.

- You may not further distribute the material or use it for any profit-making activity or commercial gain

If the publication is distributed under the terms of Article $25 \mathrm{fa}$ of the Dutch Copyright Act, indicated by the "Taverne" license above, 


\title{
Physiotherapy
}

Physiotherapy 98 (2012) 320-324

\section{Importance of correcting for individual differences in the clinical diagnosis of gait disorders}

\author{
R. Senden ${ }^{\mathrm{a}, \mathrm{b}, *}$, K. Meijer ${ }^{\mathrm{b}}$, I.C. Heyligers ${ }^{\mathrm{a}}$, H.H.C.M. Savelberg ${ }^{\mathrm{b}}$, B. Grimm ${ }^{\mathrm{a}}$ \\ a Atrium Medical Centre, Department of Orthopaedics \& Traumatology, Heerlen, The Netherlands \\ b Maastricht University, Department of Human Movement Science, Maastricht, The Netherlands
}

\begin{abstract}
Objective To quantify the effects of subject characteristics on gait parameters using acceleration-based gait analysis.

Design Cross-sectional study with a single group cohort.

Setting Hospital setting.

Participants One hundred and twenty healthy subjects (six age decade groups of 10 men and 10 women) performed a 20-m walking test.

Methods Basic gait parameters (e.g. speed) and other clinically relevant parameters (e.g. step time asymmetry) were assessed during a 20-m walking test using a tri-axial accelerometer, attached at the level of the sacrum. Subject characteristics were recorded.

Results Between $34 \%$ and $51 \%$ of the variability in gait parameters was explained by age, height and gender. Subject characteristics contributed less to the variance in step time asymmetry $\left(R^{2}=0.02\right)$, gait irregularity $\left(R^{2}=0.07\right)$ and vertical displacement of the centre of mass $\left(R^{2}=0.17\right)$. Relationships identified were comparable with previous studies (e.g. faster walking speed in men, younger and taller subjects).

Conclusions Age, height and gender are determinants of basic gait parameters, while their influence on gait irregularity and step time asymmetry is minimal. This indicates that gait is variable between subjects, showing the relevance of correcting gait for subject characteristics. This study describes preliminary work to build a database of gait parameters in healthy participants, describing the effects of age, gender and height. Further studies to extend this database with patients would provide further relevance to clinical practice.
\end{abstract}

(C) 2011 Chartered Society of Physiotherapy. Published by Elsevier Ltd. All rights reserved.

Keywords: Gait analysis; Clinical test; Clinical evaluation; Effect of subject characteristics

\section{Introduction}

Gait analysis is often used in clinical practice to investigate a subject's walking capability, assess the quality of, detect deviations from normal walking, and assist in therapeutic decision-making. Gait parameters (e.g. speed) are useful clinical indicators of well-being. Studies have shown that walking speed is associated with survival [1] and cardiovascular mortality in elderly people [2]. In addition, stride variability has been used to identify elderly people at increased risk of falls [3]. In current clinical practice, gait is assessed by doctors'

\footnotetext{
* Corresponding author at: Atrium Medical Centre, Department of Orthopaedics \& Traumatology, Henri Dunantstraat 5, Heerlen, P.O. Box 4446, 6401 CX Heerlen, The Netherlands. Tel.: +31 455766416; fax: +31 455766576 .

E-mail address: rachel.senden@bw.unimaas.nl (R. Senden).
}

visual observation. This method lacks accuracy, is affected by observer bias and is unable to identify small changes in gait. Acceleration-based gait analysis (AGA), a relatively new, objective technique for gait analysis, is feasible for clinical use, and is reliable and reproducible [4-6]. In addition, AGA is able to identify small changes in gait [4], showing its added value in clinical practice (e.g. diagnostics and evaluations).

For clinical purposes, correct interpretation of the gait pattern is required. This requires insight into the determinants of gait and the dynamics of walking. Therefore, many studies have been undertaken to investigate gait differences as a function of age, gender, height or weight. Most studies have relied on sophisticated motion analysis systems [7-10], but to the authors' knowledge, no studies have investigated the use of a single tri-axial accelerometer to examine the effect of age, gender, height and weight on various gait parameters. However, one recent study identified relationships between gait 
parameters and subject characteristics using an inertial sensor system (3D accelero- and gyrometer, attached at ankle) [11]. Studies have shown that gait changes with age, as indicated by a slower walking speed, shorter step length, lower step frequency, lower foot clearance and wider step width in elderly people $[8,11]$. In addition, typical gender differences in gait have been demonstrated. Men walk faster, take longer steps and have lower cadence compared with women $[11,12]$; the differences between genders may be explained, in part, by differences in anatomy of the pelvis and hip, and differences in height [12-14]. This indicates that gait is also influenced by height. It is well known that smaller subjects take shorter steps and walk with higher step frequencies to keep up with taller subjects, and Sutherland et al. found that the ratio of stride length to stature was similar for small and tall subjects, indicating an effect of height [15]. In addition to age, gender and height, weight has also been shown to affect gait, and it has been reported that the effect of variations in weight is greater than the effect of variations in height [16].

While the effects of subject characteristics on gait are often acknowledged, there are few data to describe these effects. Scaling methods have been introduced to adjust data for the effects of height or weight on gait. For instance, gait data in units of force, moment or power can be divided by weight to correct for differences in weight. Scaling methods for height, which mainly rely on the biomechanical model representing gait as an inverted pendulum [16], compensate by dividing gait parameters such as step length and walking speed by height or leg length [16]. Hof used leg length and gravity to correct for differences in height, obtaining a complete set of dimensionless parameters [17]. In addition, the Froude number, a dimensionless measure of walking speed, is often used to compare walking dynamics of subjects of differing statures [18]. While these scaling methods are frequently applied in practice, they only cover the effect of height or weight.

The present study aimed to explore and quantify the effects of variations in age, gender, height and weight on various gait parameters, measured by the clinically feasible AGA system.

\section{Methods}

\section{Subjects}

One hundred and twenty healthy subjects (divided into six age groups of 10 men and 10 women per age decade) were included in the cross-sectional study with a single cohort group. Subjects had a mean age of 49 (range 20 to 86) years, mean height of 1.73 [standard deviation (SD) 0.09 ] m, and mean weight of 74 (SD 13) kg. The study was approved by the Committee on Research Ethics (Local Ethical Committee, The Atrium MC Parkstad). All participants gave their informed consent. Participants were considered to be healthy if they met the criteria summarised in a self-assessment checklist (available on request).

\section{Procedure}

Each subject walked six times along a 20 -m straight length of linoleum flooring in the hospital at self-selected speed. Trunk accelerations were measured in three orthogonal directions using a small, lightweight, portable tri-axial accelerometer $(62 \times 41 \times 18 \mathrm{~mm}, 53 \mathrm{~g}, f=100 \mathrm{~Hz}$, Dynaport Minimod, McRoberts BV, The Hague, The Netherlands, Fig. 1 [19]). The accelerometer was attached tightly to the skin with adhesive tape at the level of the sacrum while performing the gait test. After walking each 20-m length, the distance by which the participant's last step extended beyond the 20-m marker was measured to obtain the exact distance walked. All subjects wore their normal shoes and clothing.

\section{Outcome measures}

Gait parameters such as step length, walking speed, cadence and other clinically relevant parameters, such as vertical displacement of the centre of mass and irregularity [average (SD step time left $+\mathrm{SD}$ step time right)], were derived from the filtered anterior-posterior acceleration signal using integration processes and peak detection
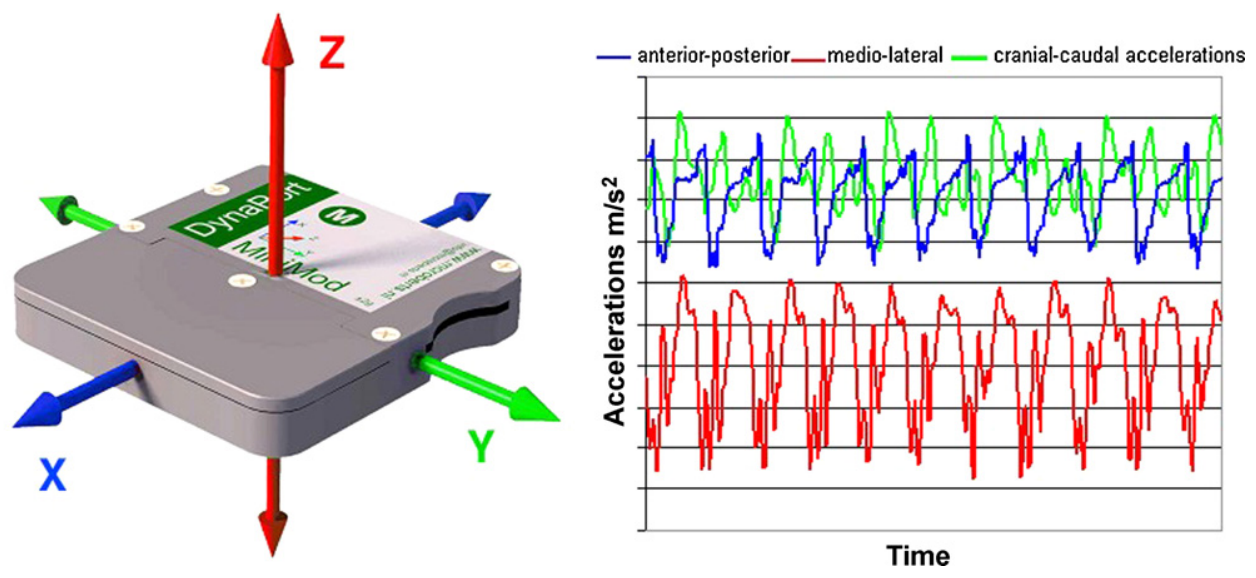

Fig. 1. Tri-axial acceleration signal of walking, recognising individual steps by peak detection. 
algorithms, analogous to those of Brandes et al. [19]. The left-right step time asymmetry $\{$ (mean step time left - mean step time right $) /[($ mean step time left + mean step time right $) / 2] \times 100\}$ was calculated using the derived step times. For each parameter, the average of the six trials was used for further analysis.

\section{Statistical analysis}

Multiple regression analysis, using the backward method, was performed to explore the relationships between age, gender, weight, height and gait parameters. Predictive models were built for walking speed, step length, cadence, vertical displacement of centre of mass, gait irregularity and step time asymmetry. All analyses were performed using SPSS Version 15.0 (IBM Corporation, NY, USA). $P<0.05$ was considered significant.

\section{Results}

Significant predictive models were formulated for all gait parameters including age, gender and height as determinants of gait. Weight was not incorporated in any model (Table 1). Step length was best predicted by subject characteristics $\left(R^{2}=51 \%\right)$ including age $(B=-0.002)$, height $(B=0.37)$ and gender $(B=-0.043)$ as determinants. This indicates that for every unit increase in height, a 0.37 unit increase in step length is predicted, holding all other variables constant. The explained variance in cadence was $41 \%$, including age $(B=-0.175)$, height $(B=-36.44)$ and gender $(B=2.97)$ as variables. Age $(B=-0.006)$ and gender $(B=-0.084)$ accounted for $34 \%$ of the variability in walking speed. The models for vertical displacement of the centre of mass, gait irregularity and step time asymmetry were less related to subject characteristics $\left(R^{2} \leq 0.17\right)$. Age and height were determinants of vertical displacement and gait irregularity. Step time asymmetry was only influenced by height.

\section{Discussion}

The current study explored the relationships between age, height, weight, gender and AGA-derived gait parameters. The magnitudes of the correlations appeared to be clinically important, although they were modest in size. The fact that height, age and gender together explained $34 \%$ to $51 \%$ of the variance in basic gait parameters, while gait is likely to depend on many more factors such as vision or environmental conditions, indicates that these subject characteristics are clearly important. These percentages are comparable with studies which showed that age, gender, height and weight are independent predictors of the distance walked during a 6-minute walk test in healthy subjects $\left(R^{2}=0.19\right.$ to 0.42$)$ $[20,21]$. In addition, the subject characteristics explained the greatest proportion of the variance in step length $\left(R^{2}=0.51\right)$, which was also found in a recent study by Schwesig et al. $\left(R^{2}=0.49\right.$ for stride length) [11]. The fact that age and height were incorporated in all models in the current study, except respectively step time asymmetry and walking speed, shows that age and height are the main determinants of gait characteristics. In addition, these models indicate that age (or height) is predictive for gait parameters, even when the effect of gender and height (or age) is taken into account. In addition to age and height, gender was found to have a considerable effect on gait parameters.

The contribution of age was shown by a decrease in step length, walking speed, cadence and vertical displacement, and an increase in gait irregularity with advancing age. These results are similar to those of previous studies which used other motion analysis techniques $[8,11]$. Height was related to step length and cadence, and indicated that taller subjects walk with longer steps and lower cadence; this has been shown previously [12]. In addition, height was positively associated with vertical displacement and gait irregularity, and negatively associated with step time asymmetry. Further analysis showed that age and height are significantly correlated $(R=-0.24)$. However, this relationship shows that only $6 \%$ of height can be explained by age, indicating an independent effect of height. This emphasises the importance of correcting gait for age and height differences when comparing gait between subjects. Gender was associated with the basic parameters in a similar way as reported previously [11], and indicated that women walk with shorter steps, higher cadence and slower walking speed than men. The gender difference in walking speed can be explained, in part, by the fact that men are significantly taller than women. This is also evident from further analysis showing that the average walking speed of men and women becomes similar ( 0.5 for men and 0.49 for women) after correcting for height [17]. Similar findings were reported by Sutherland

Table 1

Multiple regression analyses with gait parameters as the dependent variables to determine the effect of subject characteristics.

\begin{tabular}{|c|c|c|c|}
\hline & Model & Adjusted $R^{2}$ & $P$-value \\
\hline Step length $(\mathrm{m})$ & $0.228-0.002 \times$ age $+0.370 \times$ height $-0.043 \times$ gender & 0.51 & $<0.001$ \\
\hline Cadence (steps/minute) & $184.840-0.175 \times$ age $-36.437 \times$ height $+2.970 \times$ gender & 0.41 & $<0.001$ \\
\hline Speed (m/second) & $1.778-0.006 \times$ age $-0.084 \times$ gender & 0.34 & $<0.001$ \\
\hline Vertical displacement $(\mathrm{m})$ & $-0.717-0.013 \times$ age $+3.532 \times$ height & 0.17 & $<0.001$ \\
\hline Gait irregularity $(\%)$ & $-1.354+0.013 \times$ age $+1.378 \times$ height & 0.07 & $<0.001$ \\
\hline Step time asymmetry $(\%)$ & $15.585-6.900 \times$ height & 0.02 & $<0.001$ \\
\hline
\end{tabular}


et al. [15]. In addition, gait parameters were not affected by weight. This lack of relationship may be due to the relatively narrow weight range of the study population. Moreover, Alexander suggested that the effect of weight is largely due to the effect of height, since taller subjects are usually heavier [22]. More research including lean and overweight subjects is needed to further investigate the effect of weight on gait.

The subject characteristics accounted for $2 \%$ and $7 \%$ of the variability in step time asymmetry and gait irregularity, respectively. This suggests that step time asymmetry and gait irregularity are less dependent on the characteristics of healthy subjects, and are more likely to be due to the influence of a pathology. Therefore, when step time asymmetry and gait irregularity are noted, this may indicate functional abnormalities specific to the pathology [23].

At least $50 \%$ of the variation in gait parameters remained unexplained, suggesting that other factors influence gait. Studies have demonstrated that factors such as visual acuity, fear of falling, and musculoskeletal capacity including muscular strength in performing everyday activities are involved $[24,25]$. Integration of the effect of these factors could improve the prediction models. However, this results in a database requiring many measurements, making its application less practical for clinical use. Additionally, the fact that many factors influence gait indicates that gait is highly individual, which may show that it is difficult to achieve a perfect match between subjects.

This study describes preliminary work to build a database of gait parameters in healthy participants, describing the effects of age, gender and body height. This database will give further insight into the dynamics of walking, clarifying the level and proportion by which gait is affected by subject characteristics. This insight will improve the interpretation of gait, and thus contribute to improved clinical diagnostics and follow-up capabilities. In addition, the database will be relevant in clinical practice as it quickly puts the gait of patients into perspective. However, more subjects need to be included to gain more insight into the distribution and precision of the means and standard deviations of gait parameters.

The current study had some limitations. Leg length was calculated based on height, which may be imprecise. However, this is a widely used and accepted method [14] which is easy, quick and very practical for clinical use. In addition, the weight range in this study was relatively small, so the full effect of weight on gait may still be hidden. Finally, the inclusion criteria concerning health state may be too strong to obtain a representative group of elderly people as they frequently break the strict health inclusion criteria without being considered pathological due to common age-related issues that may be considered normal. However, the fact that only healthy elderly people following strict selection were included in this study is also beneficial for the database, which enables one to track deviations from normal in the older population.

\section{Conclusion}

Age, height and gender are determinants of basic gait parameters, but their influence on gait irregularity and step time asymmetry is minimal. This indicates that gait is variable between subjects, showing the importance of correcting gait for subject characteristics. This study describes preliminary work to build a database of gait parameters in healthy participants, describing the effects of age, gender and height. Further studies to extend this database with patients would provide further relevance to clinical practice.

Ethical approval: Medisch Ethische Toetsingscommissie METC - Atrium - Orbis - Zuyd. (Ref No. 07-N-31).

Conflict of interest: None declared.

\section{References}

[1] Studenski S, Perera S, Kushanger P, Rosano C, Faulkner K, Inzitari M, et al. Gait speed and survival in older adults. JAMA 2011;305: $50-8$.

[2] Dumurgier J, Elbaz A, Ducimetiere P, Tavernier B, Alperovitch ACT. Slow walking speed and cardiovascular death in well functioning older adults: prospective cohort study. BMJ 2009;339:b4460-7.

[3] Lamoth CJ, Deudekom van FJ, Campen van JP, Appels BA, Vris de OJ, Pijnappels M. Gait stability and variability measures show effects of impaired cognition and dual tasking in frail people. J Neuroeng Rehabil 2011;8:2-10.

[4] Senden R, Heyligers IC, Meijer K, Savelberg H, Grimm B. Acceleration-based motion analysis as a tool for rehabilitation: exploration in simulated functional knee limited walking conditions. Am J Phys Med Rehabil 2011;90:226-32.

[5] Senden R, Grimm B, Heyligers IC, Savelberg HHCM, Meijer K. Acceleration-based gait test for healthy subjects: reliability and reference data. Gait Posture 2009;30:192-6.

[6] Senden R, Grimm B, Meijer K, Savelberg H, Heyligers IC. The importance of including objective functional outcomes in the clinical follow up of total knee arthroplasty patients. Knee 2010 [Epub ahead of print].

[7] Kerringan DC, Todd MK, Croce UD. Gender differences in joint biomechanics during walking: normative study in young adults. Am J Phys Med Rehabil 1998;77:2-7.

[8] Nigg BM, Fisher V, Ronsky JL. Gait characteristics as a function of age and gender. Gait Posture 1994;2:213-20.

[9] Crenna P, Frigo C. Dynamics of the ankle joint analyzed through moment-angle looped suring human walking: gender and age effects. Hum Mov Sci 2011 [Epub ahead of print].

[10] Chung MJ, Wang JM. The change of gait parameters during walking at different percentage of preferred walking speed for healthy adults aged 20-60 years. Gait Posture 2010;31:131-5.

[11] Schwesig R, Leuchte S, Fischer D, Ullmann R, Kluttig A. Inertial sensor based reference gait data for healthy subjects. Gait Posture 2011;33:673-8.

[12] Cho SH, Park JM, Kwon OY. Gender differences in three dimensional gait analysis data from 98 healthy Korean adults. Clin Biomech 2004;19:145-52.

[13] van de Meent H, Jansen H, van der Linde H. Study of the human pelvis using CAT scan: gender differences and anatomy of the ramus ossis ischii. Prosthet Orthot Int 2008;32:385-9.

[14] Troosters T, Gosselink R, Decramer M. Six minute walking distance in healthy elderly subjects. Eur Respir J 1999;14:270-4.

[15] Sutherland DH, Olshen RA, Cooper L, Woo SL. The development of mature walking. J Bone Joint Surg 1980;62:336-53. 
[16] Pierrynowski MR, Galea V. Enhancing the ability of gait analyses to differentiate between groups: scaling gait data to body size. Gait Posture 2001;13:193-201.

[17] Hof AL. Scaling gait data to body size. Gait Posture 1996;4: 222-3.

[18] Zijlstra W, Prokop T, Berger W. Adaptability of leg movements during normal treadmill walking and split-belt walking in children. Gait Posture 1996;4:212-21.

[19] Brandes M, Zijlstra W, Heikens S, van Lummel R, Rosenbaum D. Accelerometry based assessment of gait parameters in children. Gait Posture 2006;24:482-6.

[20] Camarri B, Eastwood PR, Cecins NM, Thompson PJ, Jenkins S. Six minute walk distance in healthy subjects aged $55-75$ years. Respir Med 2006;100:658-65.
[21] Gibbons WJ, Fruchter N, Sloan S, Levy RD. Reference values for a multiple repetition 6-min walk test in healthy adults older than 20 years. J Cardiopulm Rehabil 1998;21:87-93.

[22] Alexander RM. Review: models and the scaling of energy costs for locomotion. J Exp Biol 2004;208:1645-52.

[23] Mizner RL, Snyder-Mackler L. Altered loading during walking and sitto-stand is affected by quadriceps weakness after total knee arthroplasty. J Orthop Res 2005;23:1083-90.

[24] Ruiz JR, Sui X, Lobelo F, Morrow JR, Jackson AW, Sjostrom M, et al. Association between muscular strength and mortality in men: prospective cohort study. BMJ 2008;337:a439.

[25] Dieën van J, Pijnappels M, Bobbert MF. Age related intrinsic limitations in preventing a trip and regaining balance after a trip. Saf Sci 2005;43:437-53.

Available online at www.sciencedirect.com $\because$ ScienceDirect 